Béatrice Galinon-Melenec, et Fabienne MartinJuchat (Dir.), Le corps communicant - Le XXI siècle, civilisation du corps?

Paris : L'Harmattan, coll. Le corps en question, 240 p, 2007, 23€

\title{
Ghyslaine Thorion
}

\section{OpenEdition \\ Journals}

Édition électronique

URL : http://journals.openedition.org/communicationorganisation/681

DOI : 10.4000/communicationorganisation.681

ISSN : $1775-3546$

\section{Éditeur}

Presses universitaires de Bordeaux

\section{Édition imprimée}

Date de publication : 1 décembre 2008

Pagination : 264-265

ISBN : 978-2-86781-582-9

ISSN : $1168-5549$

\section{Référence électronique}

Ghyslaine Thorion, «Béatrice Galinon-Melenec, et Fabienne Martin-Juchat (Dir.), Le corps communicant - Le XXIe siècle, civilisation du corps ? », Communication et organisation [En ligne], 34 | 2008, mis en ligne le 01 décembre 2008, consulté le 21 septembre 2020. URL : http://journals.openedition.org/

communicationorganisation/681 ; DOI : https://doi.org/10.4000/communicationorganisation.681 
Bibliographie

\section{Béatrice Galinon-Melenec, et Fabienne Martin-Juchat (Dir.), Le corps communicant - Le XXI ${ }^{e}$ siècle, civilisation du corps?}

Paris : L'Harmattan, coll. Le corps en question, 240 p, 2007, $23 €$

Point commun aux contributeurs de cet ouvrage : celui d'avoir participé au colloque intitulé Le corps communicant, organisé par trois groupes de recherche en Sciences de l'Information et de la Communication, et qui s'est tenu à Dijon en juin 2006. L'angle d'approche retenu pour appréhender le corps comme objet d'étude délaisse la «sémiotique gestuelle ou mimo-gestuelle » accompagnant le discours pour s'intéresser au mode de communication spécifique qu'est le corps et l'inscrit dans une «perspective structurale ». Ce cadrage donné dans l'introduction par les responsables scientifiques, permet un positionnement original et une réflexion interdisciplinaire menés sur l'analyse de pratiques corporelles. Les travaux de chercheurs (y compris de jeunes chercheurs) reflètent des contextes de communication diversifiés que le lecteur trouvera regroupés dans les chapitres : «corps et expression artistique », " corps médiatisé », « intimité, affectivité », « corps et construction de l’identité ».

Décrypter les pratiques corporelles revient à saisir les significations véhiculées par le corps, que ce soit les stéréotypes culturels contrastants suivant les lieux et les époques, le psychisme individuel voire les pathologies mentales qu'il révèle et les représentations collectives implicites qu'il suggère. Les études contenues dans cet ouvrage font état des représentations sociales et culturelles du corps à la fois dans l'espace public et dans l'espace privé. Les auteurs observent, analysent, questionnent le corps dans des champs et contextes variés : tantôt corpssujet, corps-objet, corps dans l'espace, corps voilé, dévoilé, obèse, cadavre, tantôt corps en souffrance. De la mise en peinture à la mise en bière, en passant par la mise en scène artistique, théâtrale, sportive ou sociale, le corps s'expose, s'incarne, se donne à voir et à penser. Le corps communique dans sa chair (corps tourmenté, anéanti, déformé), dans ses interactions (objet de rejet, d'humiliation, de tensions ou de désirs), dans son rapport à la société (terrorisme, inhibition, peur, plaisir), son traitement médiatique (forme, genre et apparence), sa relation au public 


\section{Bibliographie}

(rejet social, dangerosité, émotions). Même le corps passif signifie. Les représentations esthétiques, individuelles, médiatiques, symboliques, les logiques identitaires et sociales, les mises en scène de soi, la physiognomonie sont autant d'entrées pour analyser le jeu social, les rituels, les codes construits autour de notre relation au corps. Les interprétations culturelles et subjectives, la richesse et la diversité des apports, participent d'une médiation organique qui place le corps dans une dimension spatiale et temporelle; un corps intime ou social qui fait sens dans un environnement et une société donnés.

Ghyslaine Thorion 